\title{
MARKETING DE RELACIONAMENTO: IMPORTÂNCIA E IMPLICAÇÕES NO MERCADO CONSUMIDOR
}

RELATIONSHIP MARKETING: IMPORTANCE AND IMPLICATIONS IN THE CONSUMER MARKET

\section{SAMDRA SAYURI YAMASHITA}

Doutoranda em Administração de Empresas pelo Programa de Pós-Graduação em Administração da Faculdade de Economia, Administração e Contabilidade da Universidade de São Paulo (USP). Avenida Paulista, 1804, $1{ }^{\circ}$ andar - São Paulo - SP - CEP 01310-922 E-mail: sandrasy@usp.br

\section{MARIA APARECIDA GOUVÊA}

Professora Livre-Docente do Departamento de Administração da Faculdade de Economia, Administração e Contabilidade da Universidade de São Paulo (USP). Avenida Luciano Gualberto, 908, sala E1 10 - São Paulo - SP - CEP 05508-900 E-mail: magouvea@usp.br 


\section{RESUMO}

Visto pelas empresas como um modo de conquistar vantagem competitiva ou apenas de não se deixar distanciar das que já o praticam, o marketing de relacionamento possui formas diversas de se definir, apresentar, interpretar e praticar; contudo, em sua essência, visa à manutenção de clientes leais, lucrativos e duradouros, oferecendo-lhes, para tanto, valor acima dos níveis oferecidos pela concorrência. Este artigo teve como principal propósito compreender alguns aspectos delineadores da importância do marketing de relacionamento para as empresas, bem como algumas implicações desse conceito para a definição de suas estratégias. Com vistas a esse objetivo, desenvolveu-se uma pesquisa exploratória com entrevistas em profundidade junto a executivos de empresas de grande porte do mercado consumidor, em oito setores distintos. Como resultado, há um consenso geral de que uma boa filosofia de relacionamento, com postura proativa de sua parte, sem negligência do fator humano, pode ser bastante benéfica para suas estratégias. Contudo, apesar de alguns casos bem-sucedidos, muitas vezes deparam com outras prioridades, com a resistência e desinteresse dos funcionários, e com a falta de recursos, entre outros fatores desestimulantes, revelando diferentes níveis de evolução do marketing de relacionamento em sua realidade.

\section{PALAVRAS-CHAVE}

Marketing de relacionamento; Lealdade; Satisfação; Valor; Orientação para o mercado.

\section{ABSTRACT}

Viewed by the companies as a way of achieving competitive advantage or simply of not to be left behind by those which have already practiced it, relationship marketing has many different approaches in terms of definition, presentation, interpretation and practice. However, in its essence, the relationship marketing 
concept aims to the maintenance of loyal, profitable and lasting clients, offering them, for this intention, value above the competitors' offerings levels. The main purpose of this article was to understand some outlining aspects of the importance of relationship marketing to the companies, as well as some implications of this concept to their strategies definitions. To meet this objective, an exploratory research was conducted based on in-depth interviews with senior executives of leading consumer market companies, from eight different industries. As a result, there was a general acceptance by the companies that a good relationship philosophy, with proactive posture, without neglecting the human factor, can be very beneficial to their strategies. However, despite having succeeded in some cases, they frequently face other priorities, employees' resistance and lack of interest, and scarceness of resources, among other discouraging factors, illustrating different evolution stages of the relationship marketing in the organizations.

\section{KEYWORDS}

Relationship marketing; Loyalty; Satisfaction; Value; Market orientation.

\section{CONSIDERAÇÕES INICIAIS}

A expressão "marketing de relacionamento" tem sido utilizada com vários significados diferentes (Nevin, I995), sendo abordado sob uma perspectiva mais estreita, no sentido de se utilizar banco de dados para enfatizar os aspectos promocionais do marketing, ou de táticas de pós-vendas para manter o contato com o cliente após a efetivação da venda, quando, em sua essência, objetiva o desenvolvimento contínuo de um relacionamento construtivo mútuo entre a empresa e seus parceiros e clientes, não se limitando a um esforço que culmina com a efetuação de uma transação independente (SHETH; PARVATIYAR, I999). Gummesson (I999, p. 243) selecionou definições de marketing de relacionamento propostas por diversos autores (BERRY, I983, p. 25; MORGAN; HUNT, I994, p. 22; SHETH, I994; PORTER, I993, p. I4; BALLANTYNE, I994, p. 3; GRÖNROOS, I996, p. II; JACKSON, I985, p. I65)*.

Tais definições, comparadas às de outros autores (SUDHARSHAN, I995, p. I45, CHRISTOPHER et al., in BOONE; KURTZ, 200I, p. I55; VAVRA, I992, p. 40; RAVALD; GRÖNROOS, I996, p. I9), embora enfatizem diferentes aspectos 
do marketing de relacionamento, variando em escopo e ênfase, guardam entre si semelhanças e complementaridades do ponto de vista dos benefícios mútuos, da colaboração e co-produção de valor, da lealdade e do foco no estabelecimento de relações duradouras e lucrativas com os clientes, o que interfere nas políticas operacionais de grande número de diferentes funções ou atividades dentro da organização. Berry (2002, p. 73) reforça que o marketing de relacionamento, em sua melhor forma, é uma filosofia, não apenas uma estratégia; é uma maneira de pensar em clientes, marketing e criação de valor, e não apenas um conjunto de técnicas, ferramentas e táticas. Trata-se de um conceito holístico, uma soma de partes integradas que orientam as competências de marketing de uma empresa.

Tendo em vista essas idéias, a situação-problema a ser analisada por este artigo pode ser assim enunciada: qual a importância do marketing de relacionamento para as organizações e quais seus impactos? A ênfase principal do estudo se concentra nas práticas de marketing de relacionamento adotadas por empresas atuantes no mercado consumidor, em oito setores distintos, num contexto competitivo e marcado pelo crescente uso de tecnologia.

\section{REVISÃO BIBLIOGRÁFICA}

O estudo do marketing de relacionamento freqüentemente remete a alguns conceitos, como qualidade e satisfação de clientes, valor, orientação para o mercado, CRM e relacionamento pela internet. Tais conceitos, juntamente com a evolução histórica do marketing de relacionamento, embora de grande relevância para o tema deste artigo, não serão aqui tratados, dando lugar à compreensão da importância do marketing de relacionamento para as empresas, de seus impactos e de suas implicações para elas - objetos deste artigo, que passamos a examinar a seguir.

\subsection{A IMPORTÂNCIA DO MARKETING DE RELACIONAMENTO PARA A ORGANIZAÇÃO}

A abordagem do relacionamento, ao contrapor-se à ênfase na transação apresentada na literatura tradicional de marketing, representa uma mudança: para uns, uma mudança de era (BOONE; KURTZ, 200I), de estratégia (CHRISTOPHER et al. in BOONE; KURTZ, 200I, p. I55), de orientação (VAVRA, I992), ou ainda, para outros mais radicais, uma mudança de paradigma no marketing (SHETH; PARVATIYAR, I995). E como toda mudança envolve custos, Fournier et al. (I998, p. 43) questionam se o marketing de relacionamento realmente compensa. Gummesson (I999, p. 7) responde que esse conceito não só oferece um 
caminho para aumentar a retenção de clientes, mas também relacionamentos de longo prazo com vendedores, concorrentes, governos, a mídia etc., e, se utilizado com habilidade, leva a receitas maiores, custos reduzidos e melhoria da performance financeira da empresa. Embora ainda com métodos de apuração em estágio incipiente, esse autor destaca a idéia de Retorno sobre o Relacionamento (Return on Relationship, ROR), ou seja, o resultado financeiro líquido no longo prazo proporcionado pelo estabelecimento e manutenção de uma rede de relacionamentos em uma empresa.

Além da questão financeira, a mudança no horizonte estratégico é apresentada como a melhor opção de abordagem para ameaças e oportunidades geradas pelos efeitos da concorrência, e também pela ampliação do acesso à informação por parte do consumidor, lembrada por Armstrong e Hagel (in DHOLAKIA; BAGOZZI, 200I, p. I9I), Boone e Kurtz (200I, p. I4I), Gurley (in RUEFLI et al., 200I, p. 5I), McKenna (I995, p. 87), entre outros. A combinação desses dois fatores, que crescem constantemente em complexidade, desencadeia novos desafios de sobrevivência para as organizações, fato que requer o desenvolvimento de capacidades que criem vantagens competitivas para as empresas.

A seguir, elementos que atestam a importância do marketing de relacionamento para a organização, relacionados essencialmente à competitividade e à lucratividade do negócio.

\subsubsection{ACIRRAMENTO DA CONCORRÊNCIA E SOFISTICAÇÃO DAS NECESSIDADES DO CONSUMIDOR}

Para Gummesson (I999, p. 33), a concorrência parece tender a uma hipercompetição, um estado de mudança contínua e de guerrilha; é intensa, rápida e avança continuamente com rupturas das vantagens competitivas, tanto da própria empresa como de seus concorrentes. Na busca de soluções para tal fenômeno, esse autor propõe um modelo para o equilíbrio de mercado no ambiente competitivo, chamado de "equilíbrio de marketing"; sua tese é que "o foco na colaboração é a mais importante contribuição do marketing de relacionamento, com impacto tanto no gerenciamento de marketing como na economia".

Takeuchi e Quelch (I994, p. I54) relatam que algumas grandes empresas dos Estados Unidos concluíram que a operação de alta qualidade em serviço ao cliente pode ser uma forma eficaz de diferenciar a empresa de suas concorrentes, liderar o estímulo de novas vendas e desestimular a mudança para fornecedores alternativos. Apesar de conceitualmente simples, a situação de interdependência entre comprador e vendedor passa a ser fundamental a partir do momento em que se têm contextos de alta competição, já que uma das mais importantes decisões estratégicas que uma empresa toma é a base pela qual os clientes preferirão 
seu produto aos da concorrência, o que requer o desenvolvimento de uma vantagem competitiva ou diferencial (WINER, I999:52).

Há várias formas de desenvolvê-la; para Porter (1989), ela surge, em essência, do valor que uma empresa consegue criar para seus compradores e que ultrapassa o custo de fabricação pela empresa. Quanto a isso, Aaker (in WINER, I999, p. 52) observa: (I) a empresa deve gerar valor para o cliente: melhorar alguma característica ou ser relevante em algum aspecto do produto/serviço que é valorizado pelo cliente; (2) o valor adicionado deve ser percebido pelo cliente: mesmo que o produto seja melhor que o da concorrência, se o cliente não puder discernir essa diferença, não constitui uma vantagem competitiva; (3) a vantagem deve ser difícil de ser copiada; do contrário, deixa de ser vantagem. McKenna (I992, p. 45) complementa que os consumidores avaliam produtos e empresas, comparandoos a outros produtos e empresas; assim, definem uma hierarquia de valores, desejos e necessidades com base em dados empíricos, opiniões, referências obtidas por propaganda de boca e experiências anteriores com produtos e serviços, e usam essas informações para tomar suas decisões de compra.

Além dessa visão clássica do desenvolvimento de vantagens competitivas, o próprio sucesso da orientação para o marketing de relacionamento já representa uma vantagem competitiva de equacionamento difícil pela concorrência, dado que isso depende do desenvolvimento de relações de confiança, as quais demandam tempo e disciplina.

\subsubsection{AUMENTO DA LUCRATIVIDADE DA ORGANIZAÇÃO}

Em uma abordagem mais ampla e genérica, só é possível aumentar a lucratividade operacional da empresa obtendo aumento de receitas e/ou reduções de custos, incluindo-se aí as despesas e os gastos. Estudiosos do marketing de relacionamento acreditam que tal filosofia oferece bons subsídios para tanto (REICHHELD, I996; WINER, I999). No que se refere ao aumento das receitas, Vavra (I992, p. I7) avalia que, em face do atual ambiente competitivo,

o que é consideravelmente mais difícil em tal dinâmica de mercado é manter os clientes comprando regularmente uma marca ou serviço. Dados os custos decorrentes de conquistar novos clientes, a única maneira de lucrar em tal situação é aumentar o tempo de vida de compra dos clientes atuais. Portanto, a retenção de clientes é muito mais importante que a atração de clientes.

É possível que haja certo exagero nessa avaliação, se tomada isoladamente, dado que ela não se aplica a toda e qualquer situação: quando a empresa deseja 
crescer, expandir seus negócios, ela necessariamente deve aumentar sua base de clientes, pois há um limite de incremento de vendas para a base já existente.

Reichheld (I996, p. 69-70) considera clientes "certos" os que oferecem fluxos de caixa constantes e retorno rentável para o investimento da empresa nos anos seguintes, cuja lealdade pode ser conquistada e mantida. É preciso ter em mente três regras básicas: (I) alguns clientes são inerentemente previsíveis e leais, independentemente da empresa com a qual estejam fazendo negócio, simplesmente preferindo relacionamentos estáveis e duradouros; (2) alguns clientes são mais rentáveis que outros: gastam mais, pagam as contas com mais presteza e demandam menos serviço; (3) alguns clientes acharão os produtos e serviços da empresa mais valiosos e mais adequados às suas necessidades e oportunidades que os da concorrência. Quanto mais clientes pertencentes a esses grupos a empresa lograr atrair, maiores serão as suas chances de colher as recompensas que acompanham a retenção de clientes. Reichheld (I996, p. 39) estudou as razões pelas quais os clientes leais são mais lucrativos, com base nos seguintes elementos: custo de aquisição, lucro básico, crescimento da receita, custos operacionais, indicações, preço prêmio. A filosofia por trás desses componentes é que, com o passar dos anos, os seus efeitos sobre o lucro se acumulam, superando, em muito, os custos de aquisição iniciais, descontados ao valor presente líquido.

Winer (I999, p. 363) argumenta que, embora haja alguma discussão sobre a eficácia de diferentes abordagens para retenção de clientes, um grande número de profissionais e estudiosos compartilha a idéia de que é mais lucrativo manter os clientes pelo tempo mais longo possível que despender mais dinheiro para conquistar novos clientes. Shapiro e Sviokla (I994, p. 353), Reichheld (I996, p. 253) e Winer (I999, p. 2I) ressaltam a importância dos sistemas de controles permanentes que permitam auferir o valor da base de clientes, analisando conceitos como lifetime customer value, ou seja, o valor presente do fluxo de receitas que pode ser produzido por um cliente, e o valor presente líquido (VPL) do cliente, que representa o fluxo descontado de lucro, deduzido o investimento de aquisição.

Além do aumento das receitas, o marketing de relacionamento também aborda a questão da otimização dos custos recorrentes e do efeito contaminador da insatisfação de algum cliente, freqüentemente subestimado pelos administradores. Mais que a perda de oportunidade de negócios, estudos mostram o alto poder destrutivo dos clientes insatisfeitos, que não reclamam, simplesmente passam a comprar da concorrência e revelam suas queixas a outros nove clientes atuais ou potenciais, multiplicando por nove o grau de insatisfação. Além disso, a empresa passa a ter a necessidade de substituir aquele cliente por meio de dispendiosos esforços de marketing (HART et al., I994, p. 279). "Um cliente perdido vale, efetivamente, por dois: é um cliente a menos para a empresa e um cliente a mais para a concorrência”, observa Crescitelli (2003, p. 34). 
Por sua vez, Gummesson (I999, p. 12-26) questiona até que ponto é lucrativo manter um relacionamento, embora esse não deva ser necessariamente rompido somente porque há um conflito; pode, muitas vezes, ser restaurado e aprimorado, ou ser a melhor opção para ambas as partes, apesar do conflito. Reichheld e Sasser Jr. (I994, p. 347), e Booz Allen e Hamilton e Wharton School (2002, p. 2) apóiam a idéia de que desenvolver o marketing de relacionamento não significa manter servilmente todos os clientes a qualquer custo. Há clientes que a empresa não deveria tentar manter, como os volúveis que não permanecem e que não se tornam lucrativos; nem mesmo deveria investir para tentar atraí-los.

Com uma noção da importância do marketing de relacionamento, passam-se a discutir as suas implicações para as empresas no exercício de suas atividades.

\subsection{AS IMPLICAÇÕES DO MARKETING DE RELACIONAMENTO}

A abordagem do marketing de relacionamento oferece uma série de elementos que auxiliam a organização a desenvolver vantagem competitiva sustentável e aumentar sua lucratividade (WINER, I999; REICHHELD; SASSER JR., I994). Contudo, para obter sucesso, o marketing de relacionamento origina uma série de implicações de trato bastante complexo para a organização. Assim é que Fournier et al., (I998, p. 43) advertem: "o marketing de relacionamento é poderoso em teoria, mas problemático em prática”. Daí a importância do entendimento das implicações, algumas delas discutidas nesta seção, do marketing de relacionamento quando posto em prática.

\subsubsection{OS DIFERENTES NÍVEIS DE RELACIONAMENTO ENTRE A EMPRESA E SEUS CLIENTES}

As implicações do marketing de relacionamento podem também ser depreendidas por meio do entendimento das formas de relacionamento do cliente em relação à empresa e vice-versa, evidenciado por Sudharshan (I995, p. I45). Segundo Kotler (in SUDHARSHAN, I995, p. I58), os clientes podem ver as empresas como inimigos, estranhos, auxiliadores ou amigos, e, infelizmente, as empresas vêem os clientes como alvo, quando na verdade deveriam abordá-los como amigos. É interessante saber como a empresa é vista por seus clientes, e então desenvolver estratégias que forneçam uma plataforma apropriada para a construção de relacionamentos significativos. Nessa mesma linha de abordagem, Gummesson (I999, p. I0) apresenta uma escala dos modos de relacionamento que a empresa precisa promover para transformar um potencial cliente em um fiel defensor da sua marca. 
No conceito de "escada da lealdade" desenvolvido por esse autor (Figura I), o degrau mais baixo representa o contato com um prospect (cliente potencial), o qual se espera que venha a se tornar um comprador. Os compradores reincidentes passam a ser clientes; esses retornam e um relacionamento de longo prazo começa a se formar. Nos estágios seguintes, o cliente se torna um apoiador e, finalmente, um defensor de seu fornecedor.

\section{FIGURA I}

\section{A ESCADA DA LEALDADE}

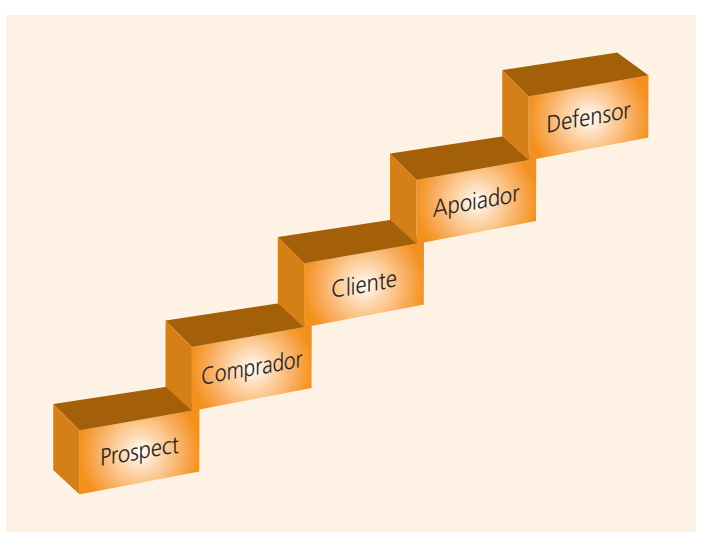

Fonte: Gummesson (I999, p. I0).

Partindo também do princípio de que os relacionamentos são construídos segundo uma seqüência lógica e progressiva, Malaviya e Spargo (2002, p. II) desenvolveram um modelo denominado Pirâmide do Relacionamento com o Cliente (Figura 2), no qual identificam seis níveis de necessidades de relacionamento. Na base da pirâmide estão os níveis de utilidade e conveniência, refletindo uma orientação racional do cliente que busca apenas um produto que atenda às suas necessidades específicas. Os dois níveis intermediários de necessidades de interação são o bem-estar e o reconhecimento pessoal, que possuem um elemento afetivo que torna a experiência de compra agradável. Os níveis mais profundos de necessidade de interação estão no topo da pirâmide - auto-expressão e criação conjunta - caracterizados por fatores pessoais e pela satisfação das necessidades racionais e afetivas, com alto nível de lealdade e confiança. 


\section{FIgURA 2}

\section{A PIRÂMIDE DO RELACIONAMENTO}

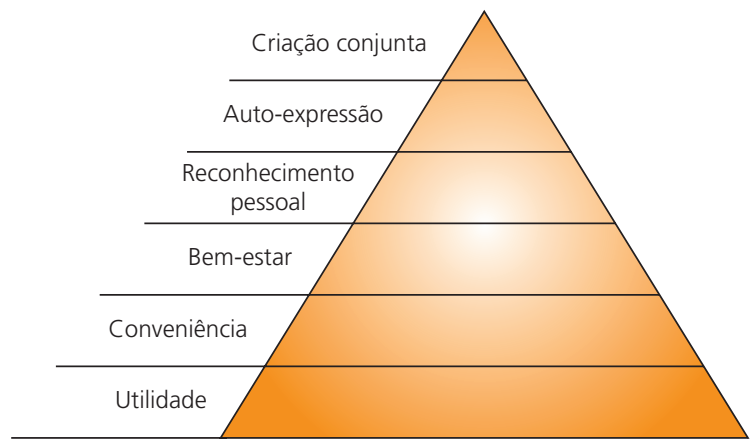

Fonte: Malaviya e Spargo (2002, p. II).

Com base nesses modelos de visão de clientes e em outros, como o de Jones e Sasser Jr. (I995, p. 88-99), que classifica os clientes em quatro categorias, segundo seu nível de satisfação e lealdade atuais, verifica-se que é crítico entender o contexto dentro do qual se está medindo lealdade e satisfação (WINER, I999, p. 366). Os clientes leais, em geral, não requerem custos adicionais de marketing ou de configuração, geralmente oferecem uma alta receita por compra, são menos sensíveis a preço e indicam novos clientes para a empresa (REICHHELD, I996). Coyles e Gokey (2002, p. I) afirmam que diferenciar e medir os graus de lealdade é uma tarefa em evolução e realizada de diferentes modos, de medidas baseadas em pesquisas junto ao cliente, como intenção de compra, a medidas comportamentais, como o porcentual de todas as compras de um produto de uma marca particular. Podem-se utilizar indicadores objetivos, como o número de reclamações (WINER, I999, p. 365), ou modelos de avaliação multiatributos, como o desenvolvido por Gale (I994, p. 3I-33).

Ao medirem o valor dos próprios clientes, algumas empresas identificaram os de mais alto valor, e aprimoraram a prevenção de partidas rumo à concorrência, pelo fornecimento, por exemplo, de serviços em níveis diferenciados (GUPTA; LEHMANN in JOHNSON, 2002, p. I6). Entre outras razões, tais informações são interessantes também como uma orientação para as estratégias de marketing: os itens nos quais o produto é superior à concorrência constituem vantagens competitivas e são parte da proposição de valor comunicada aos clientes (WINER, I999, p. 370). Além da discussão de elementos que influenciam a lealdade do cliente, deve-se também refletir sobre as formas de avaliação: as ações tomadas pela empresa com o intuito de fidelizar o cliente estão, de fato, surtindo efeito ou são apenas resultado de uma inércia determinada pela ausência de alternativas? 
Coyles e Gokey (2002, p. I) afirmam que uma boa apreciação das forças subjacentes que influenciam a lealdade dos clientes, em particular suas atitudes e necessidades em constante mutação, pode auxiliar as empresas a desenvolver esforços mais direcionados para corrigir qualquer migração negativa em seus hábitos de compra, e pode ter até dez vezes mais valor que apenas prevenir os abandonos, bem antes que eles ocorram. Entretanto, um grande número de evidências sugere que apenas satisfazer os clientes não é suficiente para mantêlos leais a uma empresa ou produto (WINER, I999, p. 366), e nem diz a uma empresa o que torna os clientes leais; nem mesmo medir os níveis de satisfação revela o quão suscetíveis seus clientes são a mudar seus hábitos de compra. Ao compreenderem por que os clientes exibem diferentes graus de lealdade, e combinarem esse conhecimento com dados sobre os modelos de compra, as empresas podem desenvolver perfis de lealdade que definem e quantificam segmentos de clientes (COYLES; GOKEY, 2002, p. 2-5). Além disso, Neal (in DOMINGUEZ, 2000, p. 62), ao analisar a relação entre satisfação e lealdade, observa que ela não é totalmente linear, havendo um ponto (nível mínimo de aceitação) abaixo do qual os índices de satisfação não se transformam em recompra, e outro ponto (nível de aceitação universal) acima do qual acréscimos de satisfação pouco adicionam à recompra.

Reichheld (I996, p. 338) acredita que a lealdade não é apenas filosofia e estratégia, e se aplica também às operações, pois oferece um conjunto de medidas práticas para a implementação da estratégia, em sua missão de criar valor duradouro. Segundo esse autor, as empresas líderes em lealdade, embora com estratégias distintas, baseiam-se nos seguintes princípios: desenvolver uma proposição de valor superior para o cliente, em relação à concorrência; encontrar o cliente certo; conquistar a lealdade do cliente; encontrar os funcionários certos: pessoas que compartilhem os valores da empresa, com talento e habilidade para alcançar níveis de produtividade e carreiras longas e satisfatórias; conquistar a lealdade do funcionário: investir maciçamente no treinamento e desenvolvimento dos funcionários, com planos de carreira e estruturas organizacionais que maximizem a validade de seu treinamento e suas habilidades; ganhar vantagem de custos com maior produtividade: estruturar os incentivos de modo que os funcionários tratem as despesas como se fossem suas; encontrar os investidores certos: escolher cuidadosamente seus investimentos e acreditar que só prosperarão quando clientes e funcionários prosperarem; conquistar a lealdade do investidor: tratar o dinheiro do investidor da mesma forma que trataria seu próprio dinheiro, o que proporciona um forte incentivo às empresas para reinvestir os lucros somente em projetos com potencial considerável de geração de valor.

O feedback, destacado no modelo genérico de relacionamento com clientes desenvolvido por Sudharshan (I995, p. I45), está intimamente relacionado com 
o contínuo aprendizado da empresa e da melhoria do relacionamento com o cliente. Na seção a seguir, evidenciam-se a sua importância e a necessidade de ouvir além do que os clientes dizem.

\subsubsection{A IMPORTÂNCIA DE OUVIR O CLIENTE}

Neste quesito, uma série de técnicas é sugerida por autores diversos. Dispositivos mais formais, como questionários, caixas para recebimento de sugestões e e-mail, são eficazes apenas quando alguém os monitora continuamente e age com rapidez em relação às reclamações e sugestões recebidas, como propõem Hart et al. (I994, p. 28I). Esses autores afirmam que o meio mais simples de obter feedback é facilitando a apresentação de queixas, como por e-mails enviados do próprio site da empresa, desde que com estrutura de atendimento adequadamente dimensionada; Boone e Kurtz (200I, p. I62) apresentam a divulgação de números de telefone de ligação gratuita como medida adicional.

Adicionalmente, o comitê de clientes, inspirado no focus group, pode gerar uma experiência de relacionamento significativa para ambos os lados. Nesses encontros, o cliente questiona, reclama, sugere, elogia ou confirma seu ponto de vista com outros clientes participantes, e a empresa explica o que é possível ou não fazer, quando poderá ser feito, limitações das possíveis ações etc. Por meio de ligações afetivas, sintonias, simpatias que acontecem em cada reunião entre os participantes, os laços entre clientes e empresa se fortalecem (HOLOVKO, I999, p. II9-I22). Algumas empresas promovem o contato direto entre funcionários dos setores de engenharia e de produção e clientes, com o propósito de desenvolver relacionamentos e laços que perdurem (LEVITT, I994, p. 5I-53).

É preciso ouvir vários grupos: os clientes atuais, os clientes potenciais e os clientes em poder da concorrência, não conquistados ou perdidos. Giangrande (I999, p. 2I) destaca a figura do ombudsman, do qual se espera que seja um facilitador no desenvolvimento do marketing de relacionamento e da cultura da qualidade nas empresas. Ele deve zelar para que os direitos do cliente sejam respeitados e suas expectativas, satisfeitas; deve agir como mediador, e não como juiz, honrando os preceitos éticos. "Ouvir o cliente e transmitir imediatamente a todas as áreas o resultado de seu contato auxilia a empresa a conhecer e a compreender como suas ações e sua postura são percebidas por seu público prioritário". A divulgação e discussão dos resultados das pesquisas de satisfação e das manifestações espontâneas dos clientes sinalizam uma atitude que pode trazer resultados bastante positivos em relação ao marketing de relacionamento, como ponderam Shapiro e Sviokla (I994, p. XVIII) e Hart et al. (I994, p. 288).

$\mathrm{O}$ marketing de relacionamento também exige preparo e adequação das pessoas envolvidas, dos processos, e da organização como um todo, como será discutido a seguir. 


\subsubsection{OUTRAS IMPLICAÇÕES}

Giangrande (I999, p. I8), Fonseca (I999, p. 56) e Cymbaum (in CYMBAUM; MÁLACCO, I999, p. 27) concordam que um dos primeiros pré-requisitos para o marketing de relacionamento é o desenvolvimento nas empresas de uma cultura de serviços, de atendimento, ou orientada aos clientes, que depende de questões como a forma pela qual a empresa quer se relacionar com eles, como deseja ser vista por eles, quais os valores implícitos no atendimento, qual a visão da empresa e do cliente sobre o binômio cliente/produto, como são tratados os clientes internos, que ações adotar para que todos estejam envolvidos, como obter feedback do atendimento oferecido, como gerar motivação para o alcance de metas e resultados, e de que modo prover capacitação para o desempenho com maior qualidade, produtividade e flexibilidade.

Winer (I999, p. 373) aponta ainda como uma forma de demonstrar excelência em serviço ao cliente a recuperação de serviços. Um momento crítico para a empresa ocorre quando um produto ou serviço não apresenta o desempenho esperado ou não funciona como deveria. A reação da empresa nessas situações é determinante para a manutenção de relacionamentos. Uma boa recuperação pode transformar clientes irados e frustrados em clientes leais. Ron Zemke (in FINKELMAN; GOLAND, I994, p. 268) descobriu em seus estudos que a boa recuperação é responsável por $38,7 \%$ das diferenças existentes entre empresas percebidas como muito boas ou muito ruins na prestação de serviços aos seus clientes. A empresa deverá criar um sistema de compensação que dê aos seus funcionários reforço positivo ao seu comprometimento e às ações capazes de solucionar problemas e, ao mesmo tempo, agradar aos clientes (HART et al., I994, p. 288).

Além do treinamento para as pessoas que interagem diretamente com seus clientes, a empresa terá que lhes delegar poderes, conferindo-lhes autoridade, responsabilidade e incentivos para que reconheçam, se interessem pelos clientes e atendam às suas necessidades (HART et al., I994, p. 287). Fonseca (I999, p. 56) ressalta que a capacitação do pessoal de atendimento se inicia com a seleção de pessoal com perfil adequado à cultura que se deseja desenvolver e segue com programas de formação, especialização e aperfeiçoamento.

Algumas empresas se utilizam de compradores contratados, geralmente um terceiro imparcial, sem experiência anterior com a empresa, para avaliar o serviço recebido: monitorar os funcionários, diagnosticar pontos com problemas no serviço ao cliente e medir o impacto do treinamento de funcionários (BOONE; KURTZ, 200I, p. I60), além de itens como tempo de resposta a e-mails, retorno de telefonemas, tempo de espera, simpatia dos atendentes (STERNE, 2000, p. 213). Analistas de mercado acreditam que essa metodologia é uma das mais efi- 
cientes para determinar a qualidade da prestação dos serviços (VASQUES, 2004, p. 27). Hutchison Jr. e Stolle (I994, p. IO6) exaltam a importância da existência de controles para os serviços prestados pela empresa, com o estabelecimento de padrões de performance, a sua medição real, uma análise do serviço prestado em relação ao padrão definido e a aplicação de medidas corretivas, se necessário, visando ao realinhamento da performance real. Whiteley (I997) e Winer (I999, p. 365) afirmam que empresas em processo mais evoluído analisam seu desempenho não apenas em relação ao próprio passado e aos desejos dos clientes, mas também em relação à performance de quem, em qualquer parte do mundo, esteja realizando melhor uma tarefa semelhante, a fim de determinar tendências em diferentes segmentos de mercado ou áreas de produtos.

Nenhuma atividade isolada é capaz de criar uma empresa voltada ao cliente. Pelo contrário, a manutenção de clientes requer que ações gerenciais coordenadas sejam implementadas ao longo do tempo para que se desenvolvam e se aprimorem os relacionamentos com clientes, ao mesmo tempo que a eficiência organizacional é incrementada (SHAPIRO; SVIOKLA, I994, p. XVI).

O relacionamento entre vendedor e comprador raramente termina quando uma venda é realizada. Esse relacionamento vai sendo intensificado cada vez mais [...] e auxilia na decisão de escolha do comprador por ocasião de sua próxima aquisição. [...] A qualidade dessa união irá depender de como o vendedor será capaz de administrar o relacionamento (LEVITT, I994, p. 4I).

\section{ASPECTOS METODOLÓGICOS DA PESQUISA}

A pesquisa em questão é de natureza exploratória, qualitativa, descritiva, com dados coletados em um estudo de campo multicasos, com realização de entrevistas em profundidade e utilização de dados secundários, sem intenção de realização de inferências estatísticas. O instrumento de coleta de dados constituiu-se de um roteiro com questões abertas, versando sobre as práticas de marketing de relacionamento e abordando aspectos como programas de fidelidade, pesquisas de satisfação, canais de comunicação, metas de satisfação, padrões para atendimento, capacitação de funcionários referente a relacionamento, avaliação de resultados etc. Os dados foram coletados entre novembro de $2002 \mathrm{e}$ abril de 2003.

O estudo se concentrou nas empresas com sede na Grande São Paulo, por ser esse um local de destaque em termos econômicos para o país. Em razão 
do interesse em examinar práticas institucionalizadas de marketing de relacionamento, optou-se por pesquisar empresas de grande porte, segundo critério de classificação do Banco Nacional de Desenvolvimento Econômico e Social (BNDES) (200I). Como sistema de referência, utilizou-se uma combinação dos rankings das cem maiores empresas não-financeiras nacionais e das cem maiores empresas não financeiras estrangeiras, publicados pela Gazeta Mercantil (2002, p. II2, II4). A amostragem foi não probabilística intencional, resultando na seleção de oito empresas, e mostrou-se indicada em razão de os objetivos da análise se voltarem à análise exploratória, motivada pela escassez de publicações que versam sobre o tema.

\section{ANÁLISE dOS DAdOS COLETAdOS}

Antes da análise, uma breve caracterização das empresas pesquisadas. Uma das empresas é fornecedora de serviços, três são empresas de comércio, e quatro, de indústria e comércio de produtos. Cinco dessas empresas constam na relação das cem maiores empresas de capital nacional do Balanço Anual da Gazeta Mercantil (2002), e cinco estão entre as cem maiores empresas da Região Sudeste, segundo a mesma publicação; todas elas ocupam posições de destaque nos respectivos rankings setoriais. Duas empresas receberam prêmios em três categorias consideradas no Prêmio Consumidor Moderno de Excelência em Serviços ao Cliente, nas edições de 2003 (CANTERO et al., 2003) e de 2004 (WERNECK, 2004). Duas das empresas entrevistadas não constavam do sistema de referência por não terem seu balanço anual publicado, mas foram selecionadas em razão do setor a que pertencem.

As empresas entrevistadas pertencem aos seguintes setores de atividade, com indicação do tempo de atividade no setor, no Brasil, em anos: Comércio varejista - supermercados (54); Indústria de veículos - montadoras (77); Serviços de logística - transportes aéreos (25); Indústria de higiene e limpeza - cosméticos (34); Serviços de comunicação - editoras de revistas (53); Indústria têxtil - cama, mesa e banho (20); Comércio varejista - produtos para cultura e lazer (4); Comércio varejista - lojas de departamento e eletrodomésticos (3). Buscou-se realizar uma apreciação crítica das informações obtidas nas entrevistas, procurando, quando pertinente, analisá-las à luz dos autores pesquisados na revisão bibliográfica.

A preocupação com o relacionamento com o cliente se reflete de formas e intensidades distintas na estrutura organizacional das empresas. Algumas delas possuem uma ou mais áreas formalmente responsáveis por seus relacionamentos; outras diluem tal responsabilidade entre várias áreas. 
Com relação a programas de fidelidade, há uma ampla gama de estratégias em atividade, que variam de acordo com as características dos produtos/serviços ofertados e disponibilidade de recursos em cada empresa. A compreensão dos diversos perfis de lealdade proposta por Coyles e Gokey (2002, p. 3-5), a qual assume que nem todos os relacionamentos podem ou devem ter a mesma duração ou o mesmo grau de intimidade, pode ser reconhecida nos depoimentos de algumas empresas como meio para definição das diferentes táticas/ações requeridas para administrar cada um dos segmentos e ampliar a lealdade dos clientes. O cliente realmente é mais fiel em razão do programa ou trata-se apenas de um comportamento inercial? Como algumas empresas declararam não avaliar efetivamente o desempenho de seus programas de fidelidade, o emprego da classificação dos clientes poderia fornecer subsídios para o aprimoramento dessas iniciativas ao orientar a elaboração de alternativas de premiação vinculadas à análise das razões que levam o cliente a se filiar, visando a um investimento realmente profícuo.

No que diz respeito às maneiras de ouvir o cliente, níveis e formas diversificados de pesquisa, bem como a abertura de vários canais para manifestação espontânea por parte dos clientes e encaminhamentos distintos das questões levantadas, têm sido praticados pelas empresas. Cabe destacar também a prática comum entre algumas empresas da utilização do "comprador oculto", como propõem Sterne (2000, p. 2I3) e Boone e Kurtz (200I, p. I60), para uma avaliação completa da experiência de compra. As empresas entrevistadas reconhecem a importância da monitoração contínua e da rapidez nas ações sobre reclamações e sugestões recebidas, como sugerem Hart et al. (I994, p. 28I). Contudo, tais atividades não estão sendo efetivamente executadas por todas as empresas entrevistadas.

Verificou-se também nos depoimentos que as empresas adotam canais e níveis distintos de disseminação aos funcionários das informações sobre as interações dos clientes; isso fornece feedback para que se valorizem as boas práticas, corrijam-se procedimentos, revejam-se posturas e deficiências e se verifique a eficácia do marketing de relacionamento. Apesar da existência de áreas para atendimento ao cliente em todas as empresas pesquisadas, é curiosa a ausência de mais ombudsmen institucionalizados, conforme defende Giangrande (I999, p. 2I), embora algumas delas tenham concordado que todos os funcionários da empresa, do porteiro ao presidente, devam atuar como ombudsman.

Em relação à definição de metas de satisfação dos clientes, poucas empresas foram objetivas em seus depoimentos, embora todas, incluindo as que não as possuem, dessem sinais de aprovar tal medida. Nota-se nas empresas um contraste entre controles bastante simples e outros mais sofisticados. Acredita-se que a definição de indicadores é realmente complexa, como expressaram alguns 
entrevistados, e deriva da maturidade da empresa em relação ao marketing de relacionamento e do que ela espera desse. O conceito de relacionamento difere entre as empresas: manter/reter clientes, satisfazer clientes para mantê-los, vender mais para os mesmos clientes ou estimular o aumento do ticket médio de compra, encantar, mais do que satisfazer os clientes, tratá-los de modo personalizado etc.

Uma reflexão sobre essas noções talvez pudesse trazer alguma luz à questão da definição de metas, considerada importante por todas as empresas entrevistadas e sugeridas por Hutchison e Stolle (I994, p. I06). Os critérios para avaliação dos itens referentes a marketing de relacionamento não foram muito detalhados por questões estratégicas, por desconhecimento do entrevistado, ou por inexistência desses. No entanto, há sinais de que alguns dos índices revelados trazem imprecisão em sua conceituação, uma vez que alguns sistemas das empresas, em fase de remodelagem, não poderiam ainda fornecer tais dados.

Da mesma forma, acredita-se que a premiação de funcionários que promovem um bom marketing de relacionamento está bastante associada à idéia que as empresas têm desse conceito e de como os seus funcionários devem incorporá-lo em suas atividades. Por sua vez, as políticas vigentes de premiação ora incentivam as boas práticas ora podem levar os funcionários a executar ações de maneira mecânica, sem comprometimento, o que pode implicar um risco: as boas práticas existem apenas enquanto a premiação existir. A premiação é positiva no sentido de reconhecer os funcionários que mais se destacam; contudo, acredita-se que um bom atendimento aos clientes deveria ser parte do padrão de atitudes de todo profissional de forma espontânea, sem o estímulo de gratificações. Embora haja empresas que premiam seus funcionários pelo bom atendimento, como recomenda a literatura, há outras que praticam a premiação sobre os resultados obtidos em vendas, por serem esses mais diretamente mensuráveis.

A definição de procedimentos padrão para tratar de reclamações e compensar os clientes por erros cometidos é muito útil, como sugerem autores como Hutchison e Stolle (I994, p. I06) e Finkelman e Goland (I994, p. 268), mesmo porque, pelo fato de as empresas pesquisadas serem de grande porte, com maior probabilidade de ocorrência de tais problemas, a falta dessas referências tornaria o seu dia-a-dia demasiadamente complicado. Em algumas delas, a escassez de procedimentos, aliada à carência de políticas, sobrecarrega a supervisão e áreas de apoio, e pode até gerar ações inadequadas ou desagradar ao cliente. Um grande desafio é definir padrões; desafio maior, porém, é controlá-los, pois isso envolve alguma complexidade na definição dos métodos de acompanhamento, executados em algumas empresas com softwares específicos.

As empresas, em geral, demonstram alguma preocupação com o treinamento de seus funcionários quanto ao atendimento ao cliente. Isso se revela cada vez 
mais um diferencial entre as empresas, na medida em que a competição se acirra e o amadurecimento dos clientes em relação a seus direitos como consumidor avança. Para enfrentar com mais segurança essa realidade, é preciso que todos os funcionários estejam preparados para "representar" a empresa perante os clientes. Os entrevistados deixaram transparecer que essa é uma responsabilidade de cujo peso nem sempre os funcionários estão cientes e para a qual freqüentemente não estão preparados. O conteúdo técnico-operacional nos treinamentos ainda parece ser prioritário para algumas empresas, que talvez assim o vejam por terem que lutar contra o intenso turn over dos postos de atendimento. No entanto, inferiu-se de alguns depoimentos que o desafio maior está no aspecto cultural e comportamental, em como incutir no pessoal da linha de frente a consciência de que o sucesso da empresa e, por conseqüência, dos seus funcionários, pode depender dos clientes.

Dessas noções talvez provenha o esmero de algumas empresas pesquisadas em promover treinamentos e reciclagens freqüentes a seus funcionários, como elementos fundamentais no fornecimento do produto ampliado da empresa; outras, apesar de considerar o treinamento essencial, ainda não conseguiram dispor de recursos para realizá-lo com maior freqüência. Uma das empresas declarou preocupar-se em selecionar pessoas com perfil acadêmico que permita prestar melhor atendimento a seus clientes; contudo, a correlação entre tal perfil e a qualidade dos serviços nem sempre é positiva. Constitui um princípio de difícil aplicação e que exige maior perspicácia das empresas a identificação, na seleção, de pessoas que estejam dispostas a se engajarem no espírito da empre$\mathrm{sa}$, conscientes da necessidade do cultivo do relacionamento com clientes, como sugerem Hart et al. (1994, p. 287) e Fonseca (I999, p. 56).

Quanto ao aspecto da personalização, tratar os clientes individualmente, conhecer suas preferências e hábitos de consumo, sugerir-lhes produtos alinhados a essas informações e fornecer-lhes o que desejam, no momento em que desejam, pode auxiliar a diferenciar a empresa de seus concorrentes. Com a evolução dos recursos tecnológicos, isso pode ser feito para praticamente todos os clientes. Entretanto, embora louvável, soa um pouco ambicioso que uma empresa ofereça, como padrão, serviços especiais a todos os seus clientes, como pretendem algumas empresas. Certos tipos de tratamento devem continuar exclusivos dos clientes VIP; do contrário, essa vantagem, do ponto de vista do cliente, deixa de existir. Assim, no confronto com a teoria, há um hiato entre o que as empresas dizem praticar e o que de fato praticam. É preciso, portanto, não confundir personalização com tratamento especial. Há algum tempo, essas expressões podiam ter significados equivalentes; no entanto, hoje, é possível oferecer produtos/serviços personalizados potencialmente a todos os clientes e serviços especiais somente aos clientes de maior valor para a empresa. 
Conforme autores como Cymbaum (in CYMBAUM; MÁLACCO, I999, p. 27) e Shapiro e Sviokla (I994, p. XVI), a construção do relacionamento com os clientes deve ser feita de maneira coordenada e integrada por toda a empresa. Alguns depoimentos sinalizam a premência de se resolverem inicialmente problemas internos para poderem avançar no relacionamento com seus clientes: em muitos casos, a "simples" reorganização do fluxo de informações, com comunicação fluida e valorização dos profissionais, pode resultar em melhor atendimento aos clientes. Não é possível desenvolver ações que afetam a corporação como um todo sem integração entre suas partes; é necessária uma complementação, e não competição entre elas.

As empresas, em geral, avaliam seu atual estágio de desenvolvimento segundo critérios bem distintos. Empresas que têm forte autocrítica, mesmo com projetos bem avançados, acreditam que ainda há muito a ser feito e não estão plenamente satisfeitas com seus programas; outras, com comportamentos mais ousados e mais recursos, acreditam que estão em um nível bem avançado de relacionamento; e outras, com menos recursos, consideram o que conseguiram uma grande vitória. Isso sinaliza que os níveis de satisfação quanto ao avanço no relacionamento com os clientes se manifestam de acordo com as ambições e as condições de cada empresa. Contudo, se, por um lado, uma forte autocrítica pode ser estimulante - caracterizando a busca pela perfeição -, por outro, pode ser desencorajadora, dependendo da maneira como for colocada. Segundo um entrevistado: "não importa o quanto se esforce, nunca chegará ao nível da perfeição", ou "a empresa nunca se dará por satisfeita".

Algumas das empresas, embora tenham demorado um pouco mais para se engajarem em relacionamentos mais consistentes, estão preocupadas em se prepararem conceitual e culturalmente para que as mudanças ocorram. Também é interessante que a empresa faça periodicamente um exercício de empatia: "se eu fosse cliente dos produtos/serviços da minha empresa, estaria satisfeito?". Nota-se que as empresas detêm conhecimento suficiente para praticar um bom marketing de relacionamento, e até intencionam fazê-lo. Contudo, muitas vezes, esbarram em outras prioridades, na resistência e desinteresse por parte dos funcionários, na falta de recursos, entre outros fatores desestimulantes.

\section{CONSIDERAÇÕES FINAIS}

Mais significativo que o tempo de atividade no setor, o que parece fazer diferença no relacionamento da empresa com seus clientes são a cultura e as idéias de sua direção no que diz respeito ao relacionamento, à sua orientação para o mercado e à sua proposição de valor para o cliente. Poder-se-ia imaginar que 
as empresas que estão há mais tempo no mercado tenderiam a dispor de mais recursos e embasamento para a implantação de programas de relacionamento. Entretanto, empresas que desde o início de suas atividades têm colocado o relacionamento como parte essencial de seu dia-a-dia mostram que é o empenho dedicado ao desenvolvimento do marketing de relacionamento que pode levar a uma maior maturidade nas relações com clientes, com mais chances de evolução e conseqüente ganho em termos de imagem e lucratividade para a empresa. A execução de muitas dessas práticas envolve, de fato, o comprometimento de recursos; no entanto, as empresas precisam definir quão comprometidas estão com o marketing de relacionamento.

Há um consenso geral entre as empresas de que uma boa estratégia de relacionamento, com postura proativa, sem negligência do fator humano, pode ser bastante benéfica para o desenvolvimento de relações. A proatividade pode existir quando a empresa procura antecipar as necessidades ou estimular as necessidades latentes de seus clientes, atuar na prevenção de possíveis problemas, evitando, assim, o mau atendimento, e trabalhar na concepção do serviço/produto para oferecer o melhor valor, aos olhos dos clientes.

Com base neste estudo, chega-se a uma reflexão acerca das práticas de marketing de relacionamento. Como padrões elevados no marketing de relacionamento podem constituir forte vantagem competitiva, estudos futuros poderiam propor modelos de definição de padrões ou sugerir indicadores de performance para o marketing de relacionamento.

\section{REFERÊNCIAS}

BANCO NACIONAL DE DESENVOLVIMENTO ECONÔMICO E SOCIAL. Porte de empresa. Rio de Janeiro, 2о०I. Disponível em: <http://www.bndes.gov.br/produtos/consulta/porte/porte.asp>. Acesso em: 25 abr. 200 I.

BERRY, L. L. Relationship Marketing of Services: perspectives from I983 and 2000. Journal of Relationship Marketing, Binghamton, v. I, n. I, p. 59-77, 2002. Disponível em: <http://harworthpressinc.com>. Acesso em: 29 set. 2003 .

BOONE, L. E.; KURTZ, D. L. Contemporary marketing. Io. ed. Orlando: Harcourt, 200 I.

BOOZ ALLEN \& HAMILTON; WHARTON SCHOOL. The customer profitability conundrum. Strategy + Business/Knowledge Wharton, White paper. [S.1.], Io Apr. 2002. Disponível em: <http:// www.strategy-business.com/media/general/sb_kw_I2-04-02.pdf>. Acesso em: I4 jan. 2003. CANTERO, C. et al. Elas são excelentes. Consumidor Moderno, São Paulo, a. 8, n. 69, p. 44-78, 2003.

CHURCHILL, G. A.; PETER, J. P. Marketing: criando valor para o cliente. São Paulo: Saraiva, 2000 . 
- MARKETING DE RELACIONAMENTO: IMPORTÂNCIA E IMPLICAÇÕES NO MERCADO CONSUMIDOR • SANDRA SAYURI YAMASHITA • MARIA APARECIDA GOUVÊA

COYLES, S.; GOKEY, T. C. Customer retention is not enough. McKinsey Quarterly, New York, n. 2, 2002. Disponível em: <http://www.mckinseyquarterly.com/article_page.asp?tk=384629:II76:IGe ar=II76eL2=IGeL3=20>. Acesso em: I8 abr. 2002.

CRESCITELLI, E. Marketing de relacionamento: um estudo sobre as relações... São Paulo, 2003. Tese (Doutorado em Administração) - Faculdade de Economia, Administração e Contabilidade, Universidade de São Paulo.

CYMBAUM, J. O.; MÁLACCO, R. L. S. Qualidade de atendimento no varejo: um desafio de recursos humanos. In: ANGELO, C. F. de; GIANGRANDE, V. Marketing de relacionamento no varejo. São Paulo: Atlas, I999. cap. 2, p. 27-4I.

DHOLAKIA, U.; BAGOZZI, R. P. Consumer behavior in digital environments. In: WIND, J.; MAHAJAN, V. Digital marketing: global strategies from the world's leading experts. New York: Wiley, 200I. cap. 7, p. I63-200.

DOMINGUEZ, S. V. Valor percebido como elemento estratégico para obter a lealdade... Caderno de Pesquisas em Administração, São Paulo, v. 7, n. 4, p. 53-64, out./dez. 2000.

FINKELMAN, D.; GOLAND, T. O caso do cliente queixoso. In: SHAPIRO, B. P.; SVIOKLA, J. J. Mantendo clientes. São Paulo: Makron Books, I994. cap. I4, p. 253-272.

FONSECA, M. A. Como preparar o pessoal de atendimento. In: ANGELO, C. F. de; GIANGRANDE, V. Marketing de relacionamento no varejo. São Paulo: Atlas, I999. cap. 4, p. 55-64.

FOURNIER, S. et al. Preventing the premature death of relationship marketing. Harvard Business Review, Boston, p. 43-50, jan./feb. I998.

GALE, B. T. Managing Customer Value. New York: Free Press, I994.

GAZETA MERCANTIL. Balanço anual. São Paulo, a. XXVI, n. 26, jun. 2002.

GIANGRANDE, V. Marketing de relacionamento e o papel do ombudsman. In: ANGELO, C. F.; GIANGRANDE, V. Marketing de relacionamento no varejo. São Paulo: Atlas, I999. cap. I, p. 15-26. GUMMESSON, E. Total relationship marketing - rethinking marketing management: from 4 Ps to 30Rs. Oxford: Butterworth Heinemann, I999.

HART, C. W. L. O poder das garantias incondicionais de serviço. In: SHAPIRO, B. P.; SVIOKLA, J. J. Mantendo clientes. São Paulo: Makron Books, I994. cap. 9, p. I6I-I78.

HART, C. W. L. et al. A lucrativa arte da recuperação de serviços. In: SHAPIRO, B. P.; SVIOKLA, J. J. Mantendo clientes. São Paulo: Makron Books, I994. cap. I5, p. 273-290.

HOLOVKO, B. I. Comitês de clientes. In: ANGELO, C. F. de; GIANGRANDE, V. Marketing de relacionamento no varejo. São Paulo: Atlas, I999. cap. 9, p. II9-I29.

HUTCHISON JR., W. M.; STOLLE, J. F. Como administrar o serviço ao cliente. In: SHAPIRO, B. P.; SVIOKLA, J. J. Mantendo clientes. São Paulo: Makron Books, I994. cap. 6, p. 95-II9.

JOHNSON, L. K. The real value of customer loyalty. MIT Sloan Management Review, Cambridge, p. I4-I7, Winter 2002.

JONES, T. O., SASSER JR., W. E. Why satisfied consumers defect. Harvard Business Review, Boston, p. 88-99, nov./dec. I995.

LEVITT, T. Após a venda ter sido realizada. In: SHAPIRO, B. P.; SVIOKLA, J. J. Mantendo clientes. São Paulo: Makron Books, I994. cap. 3, p. 4I-55.

MALAVIYA, P.; SPARGO, S. Relationing to customers: how and when to strengthen your customer relationships. INSEAD R\&D: Working Papers, Fontainebleau, 2002. Disponível em: <http:// knowledge.insead.fr/docs/2002-4I.pdf>. Acesso em: 3 jul. 2002. 
MCKENNA, R. Marketing de relacionamento: estratégias bem-sucedidas para a era do cliente. Rio de Janeiro: Campus, I992.

Real-time marketing. Harvard Business Review, Boston, Reprint 95407. july/aug. I995.

NEVIN, J. R. Relationship marketing and distribution channels: exploring fundamental issues. Journal of the Academy of Marketing Science, Miami, p. 327-334, Fall I995.

PORTER, M. E. Vantagem competitiva. Rio de Janeiro: Campus, I989.

RAVALD, A.; GRÖNROOS, C. The value concept and relationship marketing. European Journal of Marketing, Bradford, v. 30, n. 2, p. I9-30, I996.

REICHHELD, F. F. A estratégia da lealdade: a força... Rio de Janeiro: Campus, i996.

REICHHELD, F. F.; SASSER JR., W. E. Zero clientes perdidos: a qualidade chega aos serviços. In: SHAPIRO, B. P.; SVIOKLA, J. J. Mantendo clientes. São Paulo: Makron Books, I994. cap. I8, p. 335-350.

RUEFLI, T. W. et al. The digital technological environment. In: WIND, J.; MAHAJAN, V. Digital marketing: global strategies from the world's leading experts. New York: John Wiley, 200I. cap. 2, p. $46-48$.

SHAPIRO, B. P.; SVIOKLA, J. J. Mantendo clientes. São Paulo: Makron Books, I994.

SHETH, J. N.; PARVATIYAR, A. Handbook of relationship marketing. Newbury: Sage, I999.

The evolution of relationship marketing. International Business Review, [S.1.], v. 4, n. 4, p. 47I-48I, I995.

STERNE, J. Customer service on the Internet: building relationships, increasing loyalty, and staying competitive. 2. ed. New York: Wiley, 2000.

SUDHARSHAN, D. Marketing strategy: relationships, offerings, timing e resource allocation. Upper Saddle River, NJ: Prentice Hall, I995.

TAKEUCHI, H.; QUELCH, J. Qualidade é mais do que fazer um bom produto. In: SHAPIRO, B. P.; SVIOKLA, J. J. Mantendo clientes. São Paulo: Makron Books, I994. cap. 8, p. I45-I59.

VASQUES, E. Agente secreto CRM. Consumidor Moderno, São Paulo, a. 8, n. 82, p. 26-29, 2004. VAVRA, T. G. Marketing de relacionamento = Aftermarketing. São Paulo: Atlas, I992.

WERNECK, T. Festa do relacionamento. Consumidor Moderno, São Paulo, a. 8, n. 82, p. 30-46, 2004 .

WHITELEY, R. A empresa totalmente voltada para o cliente. Rio de Janeiro: Campus, I997.

WINER, S. R. Marketing management. Upper Saddle River, NJ: Prentice Hall, I999.

\section{TRAMITAÇÃO}

Recebido em 25/7/2006

Aprovado em 23/11/2006 
Copyright of Revista de Administração Mackenzie is the property of Universidade Presbiteriana Mackenzie, RAM-Revista de Administracao Mackenzie and its content may not be copied or emailed to multiple sites or posted to a listserv without the copyright holder's express written permission. However, users may print, download, or email articles for individual use. 